\title{
Management of Peritonitis as Emergency in a Tertiary Care Center
}

\author{
Vikas Chalotra', Sunil Shukla ${ }^{2}$, Aman Bharti ${ }^{3}$ \\ ${ }^{1}$ Assistant Professor, Department of General Surgery, Guru Gobind Singh Medical College \& Hospital Faridkot ,Punjab 151203, ${ }^{2}$ Senior Resident, \\ Department of General Surgery, RML, Lucknow, ${ }^{3}$ Assistant Professor, Department of General Medicine, Guru Gobind Singh Medical College \&Hospital
} Faridkot, Punjab 151203

\section{Abstract}

Background: Peritonitis is defined as inflammation of the peritoneal cavity. This study was done to know the various trends of management in peritonitis cases in Amritsar district of Punjab state of India. Subjects and Methods: In this study 50 cases of peritonitis were screened on the basis of lab investigations, X-rays(chest and abdomen), ultrasonography and abdominal aspiration whenever required. Majority of perforation peritonitis patients presented to emergency with electrolyte disturbances followed by septicemia. Investigations, X-ray chest showed air under diaphragm. Ultrasound showed free fluid,four quadrant aspiration showed nature of peritoneal fluid of perforation. Patients were initially resuscitated and managed with surgery to correct the underlying pathology. Results: Anaemia was present in $12 \%$ of cases. $22 \%$ of cases presented with septicaemia (TLC $>12000 / \mathrm{mm} 3$ ). Four quadrant aspiration analyses which showed that fecal matter was in the aspirate in $36 \%$ cases. Clear fluid was present in $22 \%$ cases. Bilious fluid was present in $12 \%$ cases. Haemorrhagic fluid was present in $4 \%$ cases, pus was present in $4 \%$ cases. No aspiration fluid was seen in $22 \%$ of cases. Conclusion: The most common site for the perforation is Terminal ileum (48.5\%), followed by Stomach (31.4\%), Duodenum (14.2\%), colon (2.8\%), jejunum (2.8\%).Fever (90\%) is the most common post-operative complication followed by Paralytic ileus (70\%) and superficial wound infections (50\%). post-operative complications are Anemia/ hypoproteinemia (10\%), Burst abdomen (2\%), Chest infections (10\%), and Anastomotic leaks (0\%).

Keywords: Peritonitis, management, septicemia.

Corresponding Author: Dr. Aman Bharti, Assistant Professor, Department of General Medicine, Guru Gobind Singh Medical College \& Hospital Faridkot, Punjab 151203

Received: October 2019

Accepted: October 2019

\section{Introduction}

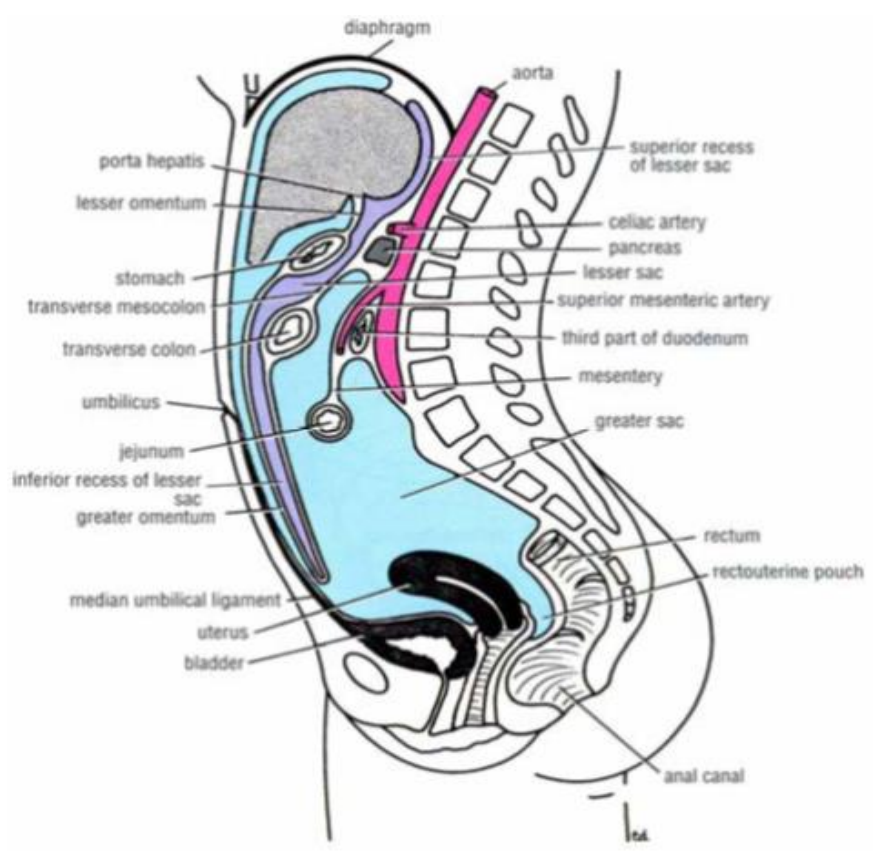

Figure 1: Sagittal section showing arrangement of peritoneum
Peritonitis is defined as inflammation of the peritoneal cavity, peritoneal inflammation caused by loss of integrity of the gastrointestinal tract with consequent leakage of the intestinal contents into the peritoneal cavity. Perforation peritonitis is the most common surgical emergency in India. Despite advances in surgical techniques, antimicrobial therapy and intensive care support, management of peritonitis continues to be highly demanding, difficult and complex. Typhoid fever is the commonest cause of ileal perforation in India. After initial resuscitation with intravenous fluids and correction of electrolyte imbalance, emergency laparotomy is performed to either repair or the resection and anastomosis of the perforated segment or exteriorization of the bowel segment bearing the perforation.

\section{Aims and Objectives}

1. To study the aids to diagnosis of peritonitis.

2. To study different methods of management of peritonitis.

\section{Subjects and Methods}

Fifty cases with provisional diagnosis of peritonitis came to the surgical emergency of Guru Nanak Dev Hospital/Govt. Medical College, Amritsar (Punjab) were reviewed. Informed consent of the patients was taken. 
The various methods of management affecting the outcome were studied. Provisional diagnoses were made from the history and clinical examination of the patients. To clinch the final diagnosis, various investigations were undertaken such as routine investigations like $\mathrm{Hb}, \mathrm{BT}, \mathrm{CT}$, TLC, DLC, ESR, Urine complete examination. Blood urea, blood sugar, serum creatinine.

Microscopic examination and culture sensitivity of the fluid taken by doing paracentesis. Radiological investigations: Xray chest (PA view) standing including both domes of diaphragm.X-ray abdomen standing position, including both domes of diaphragm, Ultrasound abdomen,CT Scan Abdomen (whenever indicated) and then respective treatment.

\section{Results}

Total of 50 patients with provisional diagnosis of peritonitis were taken up for the study. Most common causes of peritonitis were perforation(35 cases).

\begin{tabular}{l}
\hline Table 1: Showing aetiology of peritonitis \\
\begin{tabular}{|l|l|l|}
\hline Site & No. of cases & Percentage (\%) \\
\hline Perforation & 35 & 70 \\
\hline Intestinal obstruction & \multicolumn{1}{|c|}{11} & 22 \\
\hline Appendicites & 4 & 8 \\
\hline Total & 50 & 100 \\
\hline
\end{tabular}
\end{tabular}

The most common anatomical site of perforation was terminal ileum(17 cases). The next common site was stomach(11 cases) followed by duodenum(5 cases), jejunum(1 case) and colon(1 case).[Figure 1]

\section{SHOWING SITE OF PERFORATION (35 cases)}

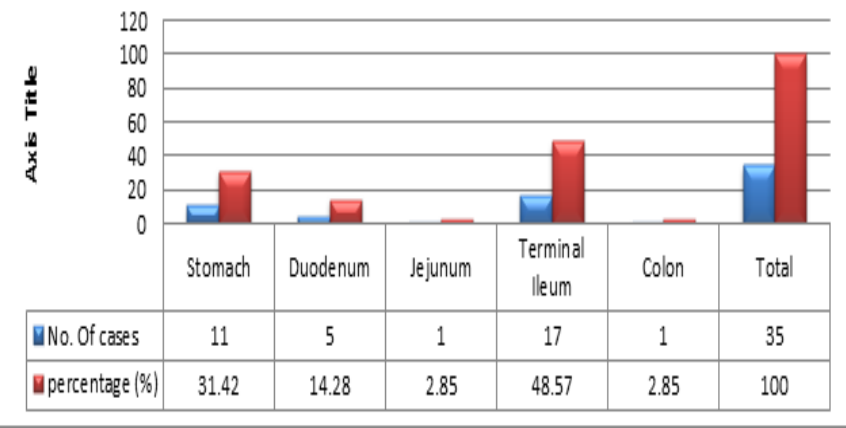

Figure 1: common anatomical site of perforation

Table 2: Showing Type of Surgical Procedure

\begin{tabular}{|c|c|c|c|c|c|c|c|c|}
\hline Aetiology & Suturing & $\begin{array}{l}\text { Omental } \\
\text { patching }\end{array}$ & $\begin{array}{l}\text { Resection \& } \\
\text { anastomosis }\end{array}$ & Appendicectomy & Cecopexy & Ileostomy & Adhesiolysis & $\begin{array}{l}\text { Peritoneum } \\
\text { lavage with } \\
\text { drain }\end{array}$ \\
\hline $\begin{array}{l}\text { Gastic } \\
\text { perforation }\end{array}$ & 11 & 11 & 0 & 0 & 0 & 0 & 0 & 11 \\
\hline $\begin{array}{l}\text { Duodenal } \\
\text { perforation }\end{array}$ & 5 & 5 & 0 & 0 & 0 & 0 & 0 & 5 \\
\hline $\begin{array}{l}\text { Jejunal } \\
\text { perforation }\end{array}$ & 1 & 0 & 0 & 0 & 0 & 0 & 0 & 1 \\
\hline $\begin{array}{l}\text { Colon } \\
\text { perforation }\end{array}$ & 1 & 0 & 0 & 0 & 0 & 0 & 0 & 1 \\
\hline Appendicular & 0 & 0 & 0 & 4 & 0 & 0 & 0 & 0 \\
\hline $\begin{array}{l}\text { Ileal } \\
\text { perforation }\end{array}$ & 13 & 0 & 4 & 0 & 0 & 6 & 0 & 17 \\
\hline $\begin{array}{l}\text { Identified } \\
\text { Obstructions }\end{array}$ & 0 & 0 & 4 & 0 & 2 & 1 & 2 & 9 \\
\hline $\begin{array}{l}\text { Not Identified } \\
\text { obstructions }\end{array}$ & 0 & 0 & 0 & 0 & 0 & 0 & 0 & 2 \\
\hline TOTAL & 31 & 16 & 8 & 4 & 2 & 7 & 2 & 46 \\
\hline
\end{tabular}

Anaemia was present in $12 \%$ of cases. $22 \%$ of cases presented with septicaemia(TLC $>12000 / \mathrm{mm} 3$ ). Electrolyte imbalance was seen in $40 \%$ cases. Four quadrant aspiration analyses which showed that fecal matter was in the aspirate in $36 \%$ cases. Clear fluid was present in $22 \%$ cases. Bilious fluid was present in $12 \%$ cases. Haemorrhagic fluid was present in $4 \%$ cases,pus was present in $4 \%$ cases. No aspiration fluid was seen in $22 \%$ of cases.[Figure 2]

Suturing of the perforation was the most common (31 cases) surgical procedure done,omental patching with suturing in 16 cases,resection and anastomosis in 8 cases.appendicectomy was done in 4 cases, ileostomy was done in 7 cases and adhesiolysis was done in 2 cases. Cecopexy was done in 2 cases with provisional diagnosis of peritonitis. In 2 cases only peritoneal lavage was done and drains were inserted in not identified or sealed perforation.

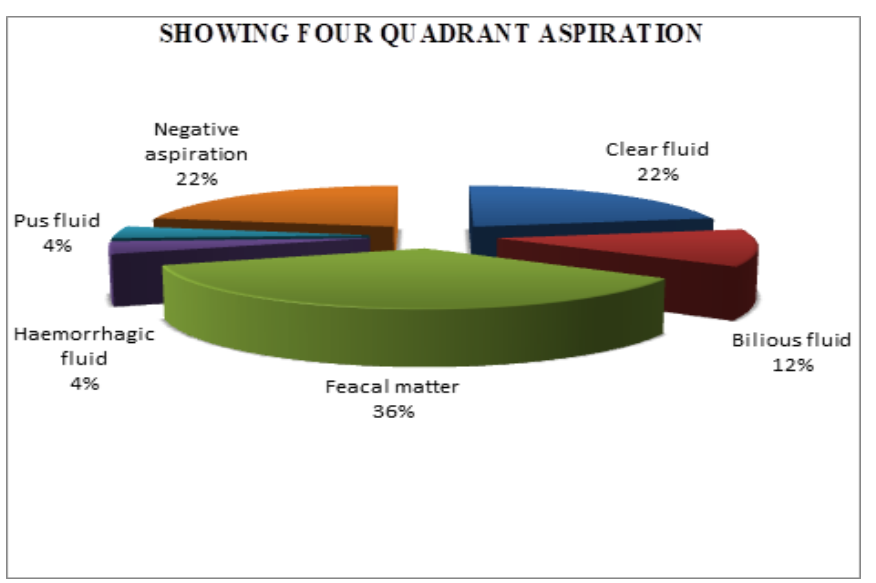

Figure 2:Four quadrant aspiration 
Fever was the most common post-operative complication(90\%), the next most common post-operative complication was paralytic ileus(70\%) and superficial wound infection was present in $50 \%$ cases. Other postoperative complications were anaemia/hypoprotenemia(20\%), burst abdomen(2\%) and chest infection(10\%). Overall mortality was $12 \%$ in this study. Mortality in ileal perforation was $17.6 \%$.[Figure 3\&4].

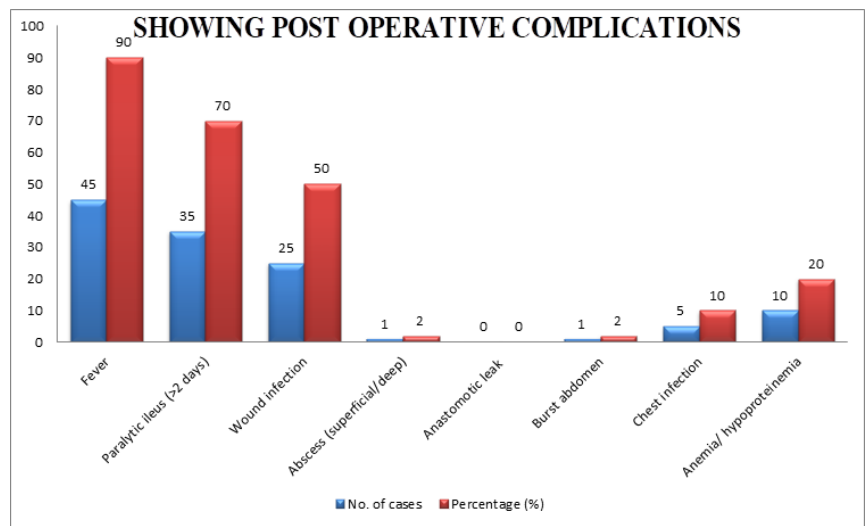

Figure 3: post-operative complications

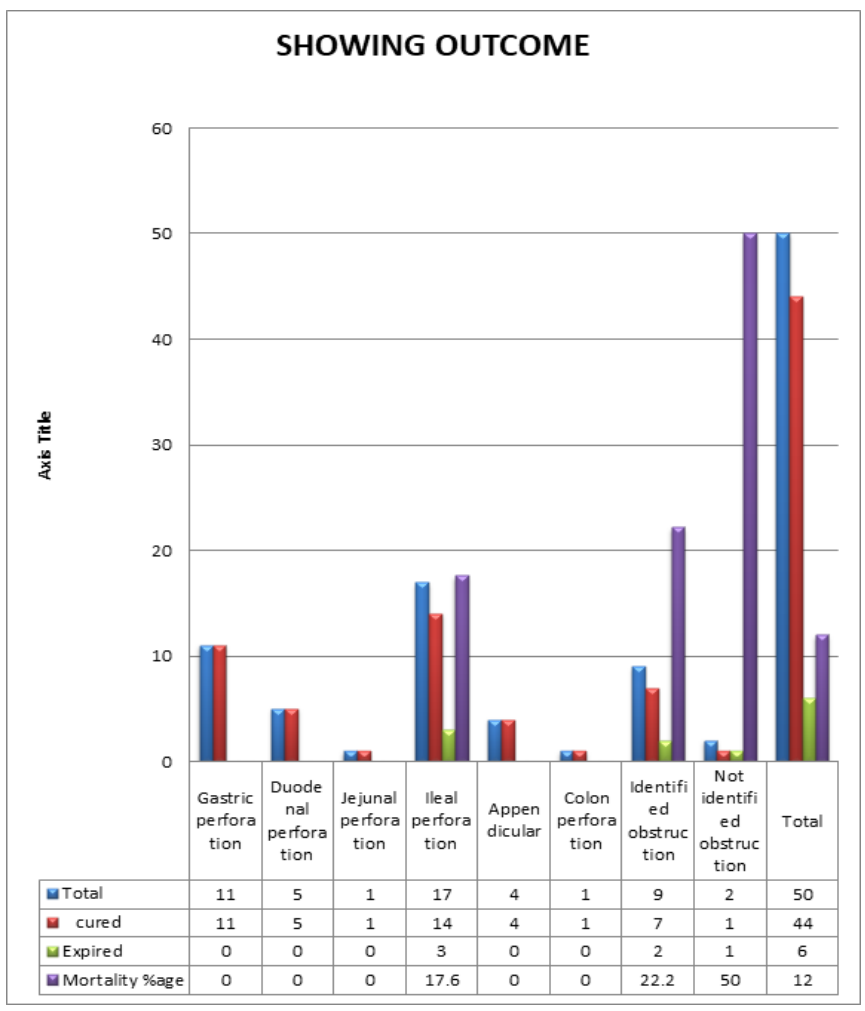

Figure 4: showing outcome

\section{Discussion}

Peritonitis is a frequently encountered surgical emergency in any Hospital with high morbidity and mortality, which continues to be a matter of great concern to the surgeons, particularly in a tropical Country like India. At the time of presentation, general condition of the patient is usually very much deteriorated and deserves skillful emergency surgical management.
The present study was undertaken to study the aids to diagnosis and management of peritonitis. In this study the most common cause of peritonitis is perforation peritonitis, various studies favour that perforation is the main cause of peritonitis.

In this study the most common $(48.57 \%)$ site of perforation was terminal ileum (up to $30 \mathrm{cms}$ proximal to ileocaecal junction) present in 17 cases out of 35 cases; next most common (31.42\%) site was stomach (11 cases out of 35 cases), other sites were 1st part of duodenum (5 cases), jejunum (1 case), colon (1 case). This study matches with the study of Agrawal $\mathrm{N}$ et al8 (most common site of perforation was ileum followed by duodenum).

$\mathrm{X}$-ray chest PA view including both domes of diaphragm in upright position is a very useful investigation to diagnose the perforation of abdominal hollow viscus by detecting pneumoperitoneum.

Table 3: Showing X-Ray Chest (Pa View) (35 Cases)

\begin{tabular}{|l|l|l|}
\hline Findings & No. of cases & Percentage (\%) \\
\hline $\begin{array}{l}\text { Air under right / both } \\
\text { domes of diaphragm }\end{array}$ & 35 & 100 \\
\hline Total & 35 & 100 \\
\hline
\end{tabular}

In this present study X-ray abdomen was done in 50 cases, pneumoperitoneum was detected in all cases of perforation peritonitis (35 cases out of 50 cases) and multiple air-fluid levels with pneumoperitoneum was the finding in 2 cases. This study is well comparable with the study of SO Fic A et al1 ( $X$ ray abdomen showed free air in the abdominal cavity in $80 \%$ cases of gastrointestinal perforation), Whereas Dickson JAS et al2 had observed air under diaphragm in $40 \%$ of abdominal $\mathrm{X}$ ray films in patients of terminal ileum perforation and Aston NO et al3 reported free peritonial gas in $25 \%$ of abdominal $\mathrm{X}$ ray films in patients of perforation.

Table 4: Showing X-Ray Abdomen (35 Cases)

\begin{tabular}{|l|l|l|}
\hline Findings & $\begin{array}{c}\text { No. of } \\
\text { cases }\end{array}$ & $\begin{array}{c}\text { Percentage } \\
(\mathbf{\%})\end{array}$ \\
\hline $\begin{array}{l}\text { Air under right / both domes of } \\
\text { diaphragm }\end{array}$ & 35 & 100 \\
\hline Multiple air fluid level & 2 & 5.71 \\
\hline
\end{tabular}

In this study USG Abdomen was done in 50 cases. The most common ultrasonographic findings were free fluid in the peritoneal cavity $(70 \%)$ and dilated gut loops with sluggish or absent peristalsis ( $22 \%$ cases).

\section{SHOWING ULTRASOUND ABDOMEN (DONE IN 50 CASES)}

घNo. of cases $\square$ Percentage (\%)

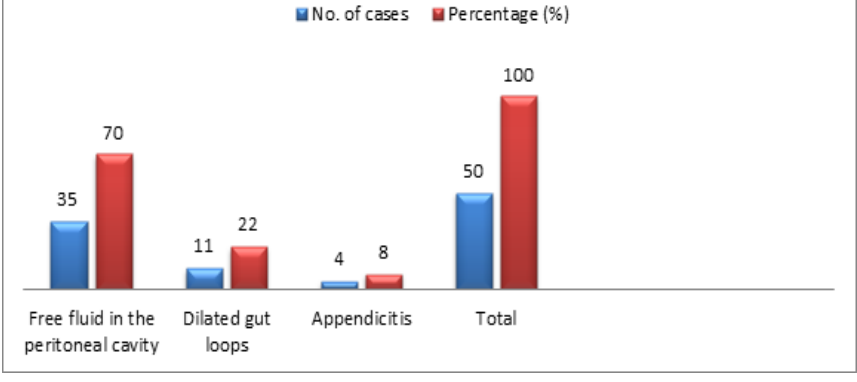




\section{Figure 5: Ultrasound abdomen}

Findings of ultrasonography in this study are well supported by the studies of SO Fic et al, ${ }^{[1]}$ (free fluid was detected in $80 \%$ cases).

In our study CECT of the abdomen was done only in two cases. SO Fic et al, ${ }^{[1]}$ had observed that CT was more sensitive to the combination of liquid and minimal amount of free air, which was undetectable with ultrasound and X-ray. In the present study management was mainly surgical. Exploratory Laparotomy was done in all cases after 3 to 4 hours of initial resuscitation.

Pre-operative Resuscitation included I.V. fluids with electrolytes, Ryle's tube aspiration and Foley's catheterization, Maintenance of input -output balance, Blood transfusion, I.V antibiotics against gram positive, gram negative and anaerobes, Monitoring of temperature, pulse and blood pressure regularly, Pre-operative intra peritoneal abdominal drain was inserted in two cases who were severely toxic and abdomen was over distended causing respiratory distress.

Pneumoperitoneum and signs of peritonitis were observed in all the cases of perforation.

Foul smelling clear fluid with or without flakes in the peritoneal cavity was observed in 11 cases; foul smelling bilious fluid with or without flakes was observed in 6 cases; foul smelling fecal matter with or without flakes was observed in 18 cases; hemorrhagic fluid was observed in 2 cases and pus was observed in 2 cases.

In 17 cases, terminal ileal perforation (up to $30 \mathrm{cms}$ proximal to the ileocaecal junction on anti-mesenteric border) was observed, In 11 cases gastric perforation was observed. In all the cases of gastric perforation it was single and present either in the pyloric region or on the anterior surface of the stomach; in 5 cases perforation was observed on the anterior wall of the first part of the duodenum; in 1 case perforation was observed on the anti-mesenteric border of the jejunum; colon perforation was observed in one case only.

The aims of surgical intervention are two fold: to drain the pus and bowel contents from peritoneal cavity and to prevent further contamination.

Minimum required operative procedure was performed. In all the cases of peptic perforation, the edges were excised and margins freshened and perforation was closed in two layers by applying at least one layer with non-absorbable suture.Pedicledomental patch was also applied in almost all the cases. Meticulous peritoneal toileting was done with normal saline. Abdominal drain was inserted in pelvic cavity and paracolic gutter.

In enteric perforation, simple closure of perforation was done with atraumatic needle in two layers/single layer. As the patients were poor surgical risk and they tolerated minimum anaesthesia, simple closure has the advantage of being quick and easy. An alternative procedure like resection and ileoileal anastomosis were also done in some cases.

In some cases of enteric perforation where the gut was not healthy enough or with multiple perforations or there was excessive soiling exteriorization of gut was done (ileostomy). Postoperatively patients were given I/V fluids, Ryle's tube aspiration, blood transfusions, antibiotics such as 3rd generation cephalosporin and metronidazole for anaerobic organisms. This treatment is recommended by most of the previous authors.

Gupta $\mathrm{S}$ et al, ${ }^{[4]}$ and other authors have also recommended the omental patching in gastro duodenal perforations.

KIM JP et al, ${ }^{[9]}$ recommended resection of small bowel in multiple typhoid perforations of the terminal ileum; he also recommended exteriorization of the small bowel in very sick patients.

Sweetman $\mathrm{R}$ et al, ${ }^{[5]}$ Aston $\mathrm{NO}$ et al, ${ }^{[3]}$ had also recommended resection of the segment of ileum as the treatment of choice in case of tubercular perforations.

Gupta SK et al, ${ }^{[6]}$ had also recommended the primary closure of the traumatic perforations. Town send MC et al10 had also recommended the primary colure of the traumatic perforations.

In this study fever was the most common post-operative complication which was presented in $90 \%$ of the patients. 2nd most common post-operative complication was paralytic ileus (for $>2$ days) which was presented in $70 \%$ of the patients. Other post-operative complications were superficial wound infections (50\%), anemia/hypoproteinemia (20\%), burst abdomen $(2 \%)$, chest infections $(10 \%)$ and anastomotic leaks $(0 \%)$.

Whereas in the study of Gupta SK et al 6common morbidity encountered were chest infection (39 cases), wound infection (12 cases), biliary leak ( 8 cases), intra-abdominal abscesses( 6 cases), burst abdomen (6 cases), reanl failure (2 cases), DIC (4 cases), jaundice and upper gastro intestinal bleeding (1 case each).

In the study of Agrawal $\mathrm{N}$ et al, ${ }^{[8]}$ incidence of major complications was $25 \%$ (burst-11\%, leak-5\%, intraabdominal abscess $5 \%$ and multi-organ failure-6.5\%). In the study of Jain BK et al, ${ }^{[15]}$ superficial wound infection $(46.8 \%)$ was the most frequent post-operative complication followed by wound dehiscence $(31.3 \%)$ and enterocutaneous fistula/leak (11.5\%).

The overall mortality in the present study is $12 \%$. The causes of mortality in the present series are very poor general condition of the patient at the time of admission, anaemia, toxaemia, dehydration and patients reported late after the perforation.

\section{Conclusion}

The most common site for the perforation is Terminal ileum (48.5\%), followed by Stomach (31.4\%),Duodenum (14.2\%), colon (2.8\%), jejunum $(2.8 \%)$.

Diagnosis is made by clinical examination and confirmed by the detection of pneumoperitoneum on X-ray chest/ abdomen, ultasonography of the abdomen and often by the four quadrant aspiration.

Laparotomy and closure of the perforation is still the commonest surgical procedure done in the ileal and jejunal perforations. Omental patching is the commonest surgical procedure done in the peptic perforations.

Peritoneal toilet and lavage with normal saline is the essential component of all the surgical procedures in perforation peritonitis. Resection\& Anastomosis and Ileostomy are the surgical procedures done in case of multiple ileal perforations and/ or in case of unhealthy, oedematous bowel wall. 
Fever $(90 \%)$ is the most common post-operative complication followed by Paralytic ileus (70\%) and superficial wound infections (50\%). other post-operative complications are Anemia/ hypoproteinemia (10\%), Burst abdomen (2\%), Chest infections (10\%), and Anastomotic leaks $(0 \%)$. Overall mortality in perforation peritonitis is $12 \%$.

\section{References}

1. Sofic A, Beslic S, Linceder L, Vrcic D. Early radiological diagnostics of gastrointestinal perforation. RadiolOncol 2006; 40 (2):67-72.

2. Dickson JAS and Cole GJ. Perforation of terminal ileum: A review of 38 cases. BJS 1964; 12: 893-7.
3. Aston NO, de Costa AM. Tuberculous perforation of the small bowel. Postgrad Med J 1985; 61: 251-52.

4. Gupta S, Kaushik R, Sharma R, Attri A. The management of large perforations of duodenal ulcers. BMC Surg 2005; 5:15.

5. Sweetman WR and Wise RA. Acute perforated tuberculous enteritis: Surgical treatment. Ann Surg 1959; 149: 143-48.

6. Gupta SK, Gupta R, Singh G, Gupta S. Perforation Peritonitis: A Two Year Experience. JK Science 2010; 12 (3): 141-44. www.jkscience.org

7. Townsend MC, Pelias ME. A technique for rapid closure of traumatic small intestine perforations without resection. Am J Surg 1992; 164 (2): 171-2.

8. Agarwal N, Saha S, Srivastava A, Chumber S, Dhar A, Garg S. Peritonitis:10years' experience in a single surgical unit. Tropical Gastro 2008, pp. 1-6.

9. Kim JP, Oh SK, Jarrett F. Management of ileal perforation due to typhoid fever. Ann Surg 1975; 181: 88-91.

Copyright: (c) the author(s), 2019. It is an open-access article distributed under the terms of the Creative Commons Attribution License (CC BY 4.0), which permits authors to retain ownership of the copyright for their content, and allow anyone to download, reuse, reprint, modify, distribute and/or copy the content as long as the original authors and source are cited.

How to cite this article: Chalotra V, Shukla S, Bharti A. Management of Peritonitis as Emergency in a Tertiary Care Center. Acad. J Surg. 2019;2(2):10-14.

DOI: dx.doi.org/10.21276/ajs.2019.2.2.3

Source of Support: Nil, Conflict of Interest: None declared. 